\title{
Effect of Incorporation of Different Levels of Algal Oil in Rice Based Ready to Eat Breakfast Cereal Mix
}

\author{
Laishram Suraj Singh $^{1 *}$, Anamika Das ${ }^{1}$, S.G.M Prasad ${ }^{1}$, \\ Pratishtha Srivastava $^{2}$, O. Chaoba Devi ${ }^{3}$ and John David ${ }^{1}$ \\ ${ }^{1}$ WCDT, SHUATS, Prayagraj (U.P.), India \\ ${ }^{2}$ ITM, Gwalior M.P., India \\ ${ }^{3}$ Thoubal College Thoubal (Manipur), India \\ *Corresponding author
}

\section{Keywords \\ Ready-to-eat cereal mix, Black rice, \\ Algal oil, \\ Organoleptic \\ analysis \\ Article Info \\ Accepted: \\ 15 December 2019 \\ Available Online: \\ 20 January 2020}

It is known that a plethora of clinical and epidemiological evidence relates to the beneficial effects of omega-3 fatty acids, as in fatty fish, and is especially strong in neurocognitive disease. Many authorities have made recommendations for intake of EPA and DHA because of their significant role in development, health and disease prevention. A ready-to-eat breakfast cereal mix was formulated by blending of roasted aromatic black rice and glutinous white rice was mixed with SMP, sugar, cocoa powder and Algal oil in different combinations. The contents of SMP, sugar, cocoa powder was constant for all the treatments. Four treatments namely $T_{A}, T_{B}$, $\mathrm{T}_{\mathrm{C}}, \mathrm{T}_{\mathrm{D}}, \mathrm{T}_{\mathrm{E}}$ and $\mathrm{T}_{\mathrm{F}}$ were studied for its physico-chemical and organoleptic analysis. The black rice: white rice ratio combinations of the treatments are 60:40 for $\mathrm{T}_{\mathrm{A}}$ and $\mathrm{T}_{\mathrm{B}}, 80: 20$ for $\mathrm{T}_{\mathrm{C}}$ and $\mathrm{T}_{\mathrm{D}}$ and 100:00 $\mathrm{T}_{\mathrm{E}}$ and $\mathrm{T}_{\mathrm{F}}$ respectively. The level of algal oil was maintained at $2 \%$ for treatment $\mathrm{T}_{\mathrm{A}}, \mathrm{T}_{\mathrm{C}}$ and $\mathrm{T}_{\mathrm{E}}$ while the level was kept at $3 \%$ for treatments $\mathrm{T}_{\mathrm{B}}, \mathrm{T}_{\mathrm{D}}$ and $\mathrm{T}_{\mathrm{F}}$. The sensory analysis of the products was conducted by using 9point Hedonic scale by a team comprising of five judges. The scores revealed that $\mathrm{T}_{\mathrm{A}}$ scores the highest in flavour and Organoleptic analysis. Therefore, treatment $\mathrm{T}_{\mathrm{A}}$ was considered as the optimized product. Omega three fatty acids derived from algal oils emerging as a new functional ingredient and is being accepted by the consumers because of its health benefits. 


\section{Introduction}

Breakfast is known to be the most important meal of the day. A ready-to-eat breakfast cereal is a food made from more or less processed grains. Consumption of breakfast provides energy for the brain and enhances learning. Eating of breakfast are also on one of the prominent provider of micro and macro nutrients. Incorporation of Algal oil in the food also makes the food rich in essential fatty acids.

The present investigation is to study the quality characteristics of ready-to-eat breakfast cereal mix prepared by mixing different combination of black rice and algal oil. Black rice has a good therapeutic value and is used for the treatment and it helps in prevention of diseases associated with chronic inflammation. Antioxidants of black rice help to preventing premature skin ageing and also promotes good health of the hair and skin.DHA and AA are the major PUFA in the membranes of brain and retinal cells and they have an impact on neuronal functions (Alessandri et al., 2004). Moreover, DHA is essential for improving memory and learning ability as it is associated with brain functioning.

\section{Materials and Methods}

\section{Procurement of materials}

Roasted black rice and roasted glutinous white rice was collected from local market of Imphal, Manipur. Algal oil was procured from Vasta Biotech, Chennai.

Sugar was purchased from local market of Allahabad. SMP was procured from AMUL. Cocoa powder was procured from Wiekfield, Nalagarh, Himachal Pradesh. Multi Mineral mix cum vitamin mix was procured from DSM, Chandigarh.

\section{Preparation of ready to eat breakfast cereal mix}

The manufacturing process for preparing the Black rice based ready-eat breakfast cereal mix is discussed below. The two roasted rice were uniformly mixed. Then the rice was heated to $40-45^{\circ} \mathrm{C}$ for 5 minutes. The roasted and grounded black rice and white rice were blended with powdered sugar @ 10\%, SMP @ 25\%, cocoa powder @ 5\%, mineral mix cum vitamin mix 2\% and algal oil@ 2\% and 3\%. The product was uniformly mixed. Different treatments were formulated using different ratio of black rice and white rice. The different treatments were $T_{A}, T_{B}, T_{C}$, and $T_{D}$ having a Black rice: White rice ratio combinations for $\mathrm{T}_{\mathrm{A}}$ and $\mathrm{T}_{\mathrm{B}}$, are of 60:40 and 100:00 having $2 \%$ algal oil while $\mathrm{T}_{\mathrm{C}}$, and $\mathrm{T}_{\mathrm{D}}$ also has a 60:40 and 100:00 but both having 3\% algal oil. The present study was conducted to evaluate the effect of incorporation of algal oil in ready-toeat foods on physico-chemical and organoleptic properties.

\section{Physico-chemical analysis}

Carbohydrates (\%) was determined by LaneEyon Method described in IS: 1479, part ii (1961). Fat analysis was carried out according to the method of AOAC (1990). Protein estimation of sample was carried out using Kjeldahl method (AOAC, 2000). The total solid content of the ready-to- eat breakfast cereal mix was estimated by (Ranganna, 2009). The Ash content of Ready-to-eat breakfast cereal mix sample was estimated by the charring method described by AOAC (2000). Crude Fibre (\%) Crude fiber of the Ready-to-eat breakfast cereal mix sample was estimated by the method given by AOAC, 2000. The Titratable acidity of the Ready-toeat breakfast cereal mix sample was estimated lactic acid as described in Ranganna (2009).

Loose bulk density, Packed bulk density and Flowability was analysed as per the method as 
described by Bandyopadhyay et al., (2016). Dispersibility was determined by the method described by Kulkarni et al., (1991). Wettability and oil absorption capacity Emulsification capacity and Gelatinization temperature was estimated as per the method described by Onwuka (2005). Foaming capacity and stability of the flour samples were studied according to the methods described by Desphande et al., (1982). The viscosity of the samples was determined with a Brookfield dial viscometer. Insolubility index analysis by the method in IS: SP: 18(Part XI), (1981). Colour L*, $\mathrm{a}^{*}$ and $\mathrm{b}^{*}$ (Hunterlab, Hunter Associates Laboratory, Reston, Verginia USA) the values were analyzed by Hunter Colourrimeter.

\section{Sensory analysis}

The evaluation was done by a 5 trained panelists at Warner College of Dairy Technology, SHUATS, Allahabad. Judgments for Ready-to-eat breakfast cereal mix were carried out through rating products on a 9point hedonic scale (Ranganna, 2009).

\section{Statistical analysis}

Statistical analysis all the experiments were conducted in triplicate and the mean and standard deviation were calculated using MS Excel software and WASP. The data were subjected to one-way analysis of variance (ANOVA).

\section{Results and Discussion}

\section{Effect of algal oil supplementation of} chemical properties

From the above investigation the physicochemical properties of the different treatments are observed as the following. Carbohydrate content was observed to be 66.96, 65.70, $65.93,65.071,64.91$ and 64.21 respectively in the treatments of $T_{A}, T_{B}, T_{C}, T_{D}, T_{E}$ and $T_{F}$. The Fat percent was observed to be 3.81, 4.81, $4.05,50.1,4.33$ and 5.31respectively in the treatments of $T_{A}, T_{B}, T_{C}, T_{D}, T_{E}$ and $T_{F}$. While the Protein percent was observed to be 19.69, $19.66, \quad 20.09, \quad 20.09, \quad 20.36 \quad$ and 20.30respectively in the treatments of $\mathrm{T}_{\mathrm{A}}, \mathrm{T}_{\mathrm{B}}$, $T_{C}, T_{D}, T_{E}$ and $T_{F}$ respectively. Total solid percent was observed to be $94.53,94.54$, $95.58,94.59,94.64$ and 94.65 respectively in the treatments of $\mathrm{T}_{\mathrm{A}}, \mathrm{T}_{\mathrm{B}}, \mathrm{T}_{\mathrm{C}}, \mathrm{T}_{\mathrm{D}}, \mathrm{T}_{\mathrm{E}}$ and $\mathrm{T}_{\mathrm{F}}$. Ash percent was observed to be. 5.12, 4.98, 5.20, 5.21, 5.43 and 5.50respectively in the treatments of $T_{A}, T_{B}, T_{C}, T_{D}, T_{E}$ and $T_{F}$ Crude Fibre percent was observed to be $0.52,0.51$, $0.68,0.66,0.811$ and 0.79 in the treatments of $\mathrm{T}_{\mathrm{A}}, \mathrm{T}_{\mathrm{B}}, \mathrm{T}_{\mathrm{C}}, \mathrm{T}_{\mathrm{D}}, \mathrm{T}_{\mathrm{E}}$ and $\mathrm{T}_{\mathrm{F}}$ respectively.

Titratable acidity percent was observed to be $0.245, \quad 0.240, \quad 0.248, \quad 0.243, \quad 0.243$ and 0.245 respectively in the treatments of $T_{A}, T_{B}$, $\mathrm{T}_{\mathrm{C}}, \mathrm{T}_{\mathrm{D}}, \mathrm{T}_{\mathrm{E}}$ and $\mathrm{T}_{\mathrm{F}}$. From the above observations it can be observed that the values of Carbohydrate decreases with the increase level of black rice and algal oil. The values of parameters such as Fat, Protein, Total solid, Ash and Crude fibre showed increasing order with the increase level of black rice and algal oil. Whereas the Titratable acidity values were not dependent of increase or decrease level of both black rice and algal oil.

The Loose bulk density values were observed as $0.45,0.44,0.44,0.43,0.44$ and 0.43 for treatments for $\mathrm{T}_{A}, \mathrm{~T}_{\mathrm{B}}, \mathrm{T}_{\mathrm{C}}, \mathrm{T}_{\mathrm{D}}, \mathrm{T}_{\mathrm{E}}$ and $\mathrm{T}_{\mathrm{F}}$ respectively.Packed bulk density values were observed as $0.56,0.55,0.55,0.54,0.55$ and 0.54 in the treatments of $\mathrm{T}_{\mathrm{A}}, \mathrm{T}_{\mathrm{B}}, \mathrm{T}_{\mathrm{C}}, \mathrm{T}_{\mathrm{D}}, \mathrm{T}_{\mathrm{E}}$ and $\mathrm{T}_{\mathrm{F}}$ respectively. Flowability values was observed as 1.25, 1.25, 1.25, 1.25, 1.25 and 1.25 in the treatments of $T_{A}, T_{B}, T_{C}, T_{D}, T_{E}$ and $\mathrm{T}_{\mathrm{F}}$ respectively. Dispersibility values was observed as84.03, 83.08, 79.03, 78.07, 72.49 and 71.54in the treatments of $T_{A}, T_{B}, T_{C}, T_{D}$, $\mathrm{T}_{\mathrm{E}}$ and $\mathrm{T}_{\mathrm{F}}$ respectively. 
Wettability values were observed as 1.49 , $1.42,1.68,1.61,1.82$ and 1.81 in the treatments of $T_{A}, T_{B}, T_{C}, T_{D}, T_{E}$ and $T_{F}$ respectively. Fat absorption capacity values were observed as $1.12,1.18,1.21,1.24,1.34$ and 1.36in the treatments of $\mathrm{T}_{\mathrm{A}}, \mathrm{T}_{\mathrm{B}}, \mathrm{T}_{\mathrm{C}}, \mathrm{T}_{\mathrm{D}}, \mathrm{T}_{\mathrm{E}}$ and $\mathrm{T}_{\mathrm{F}}$ respectively. Foaming capacity values were observed as1.93, 1.96, 2.12, 2.14, 2.36 and 2.38 in the treatments of $\mathrm{T}_{\mathrm{A}}, \mathrm{T}_{\mathrm{B}}, \mathrm{T}_{\mathrm{C}}, \mathrm{T}_{\mathrm{D}}, \mathrm{T}_{\mathrm{E}}$ and $\mathrm{T}_{\mathrm{F}}$ respectively. Emulsification capacity values were observed as58.40, 58.40, 63.00,62.20,66.60 and 66.80in the treatments of $\mathrm{T}_{\mathrm{A}}, \mathrm{T}_{\mathrm{B}}, \mathrm{T}_{\mathrm{C}}, \mathrm{T}_{\mathrm{D}}, \mathrm{T}_{\mathrm{E}}$ and $\mathrm{T}_{\mathrm{F}}$ respectively. Gelatinization temperature values were observed as75.00, 74.90, 76.10, 76.40, 78.00 and 78.50in the treatments of $\mathrm{T}_{\mathrm{A}}, \mathrm{T}_{\mathrm{B}}, \mathrm{T}_{\mathrm{C}}, \mathrm{T}_{\mathrm{D}}$, $\mathrm{T}_{\mathrm{E}}$ and $\mathrm{T}_{\mathrm{F}}$ respectively. Viscosity values were observed as $0.278,0.271,0.238,0.234,0.191$ and 0.18 in the treatments of $T_{A}, T_{B}, T_{C}, T_{D}$, $\mathrm{T}_{\mathrm{E}}$ and $\mathrm{T}_{\mathrm{F}}$ respectively.Colour $\mathrm{L}^{*}$ values were observed as 67.23, 67.20, 66.33, 65.41, 65.69 and 64.29in the treatments of $\mathrm{T}_{\mathrm{A}}, \mathrm{T}_{\mathrm{B}}, \mathrm{T}_{\mathrm{C}}, \mathrm{T}_{\mathrm{D}}$, $\mathrm{T}_{\mathrm{E}}$ and $\mathrm{T}_{\mathrm{F}}$ respectively. Colour $\mathrm{a}^{*}$ values were observed as 8.24, 8.16, 8.54, 8.45, 8.78 and 8.74 in the treatments of $\mathrm{T}_{\mathrm{A}}, \mathrm{T}_{\mathrm{B}}, \mathrm{T}_{\mathrm{C}}, \mathrm{T}_{\mathrm{D}}, \mathrm{T}_{\mathrm{E}}$ and $\mathrm{T}_{\mathrm{F}}$ respectively. Colour $\mathrm{b}^{*}$ values were observed as12.16, 12.32, 12.52, 12.64, 12.79 and 12.88 in the treatments of $T_{A}, T_{B}, T_{C}, T_{D}$, $\mathrm{T}_{\mathrm{E}}$ and $\mathrm{T}_{\mathrm{F}}$. respectively. Insolubility index values were observed as $1.84,1.80,1.72,1.70$ , 1.64 and 1.58 in the treatments of $\mathrm{T}_{\mathrm{A}}, \mathrm{T}_{\mathrm{B}}, \mathrm{T}_{\mathrm{C}}$, $T_{D}, T_{E}$ and $T_{F}$ respectively. For Loose bulk density and Packed bulk density the values showed a decreasing order with the increased level of black rice and increase level of algal oil. Whereas the Flowability value remained unchanged for all treatments. The values of Dispensability were observed to be decreasing with increased level of black rice. The values of Wettability were observed to be increasing with increased level of black rice.For parameters such as the Fat absorption capacity, Foaming capacity. Emulsification capacity and Gelatinization temperature the values showed a trend of increasing order with the increase level of black rice and algal oil. The values of Colour L* Colour a* values was observed to be decreasing with the increase level of black rice whereas the values Colour $b^{*}$ values was observed to be increasing with the increase level of black rice. For Insolubility properties it was observed to be decreasing with increased level of black rice and algal oil.

Fig.1 Graph representing average sensory scores in different treatments

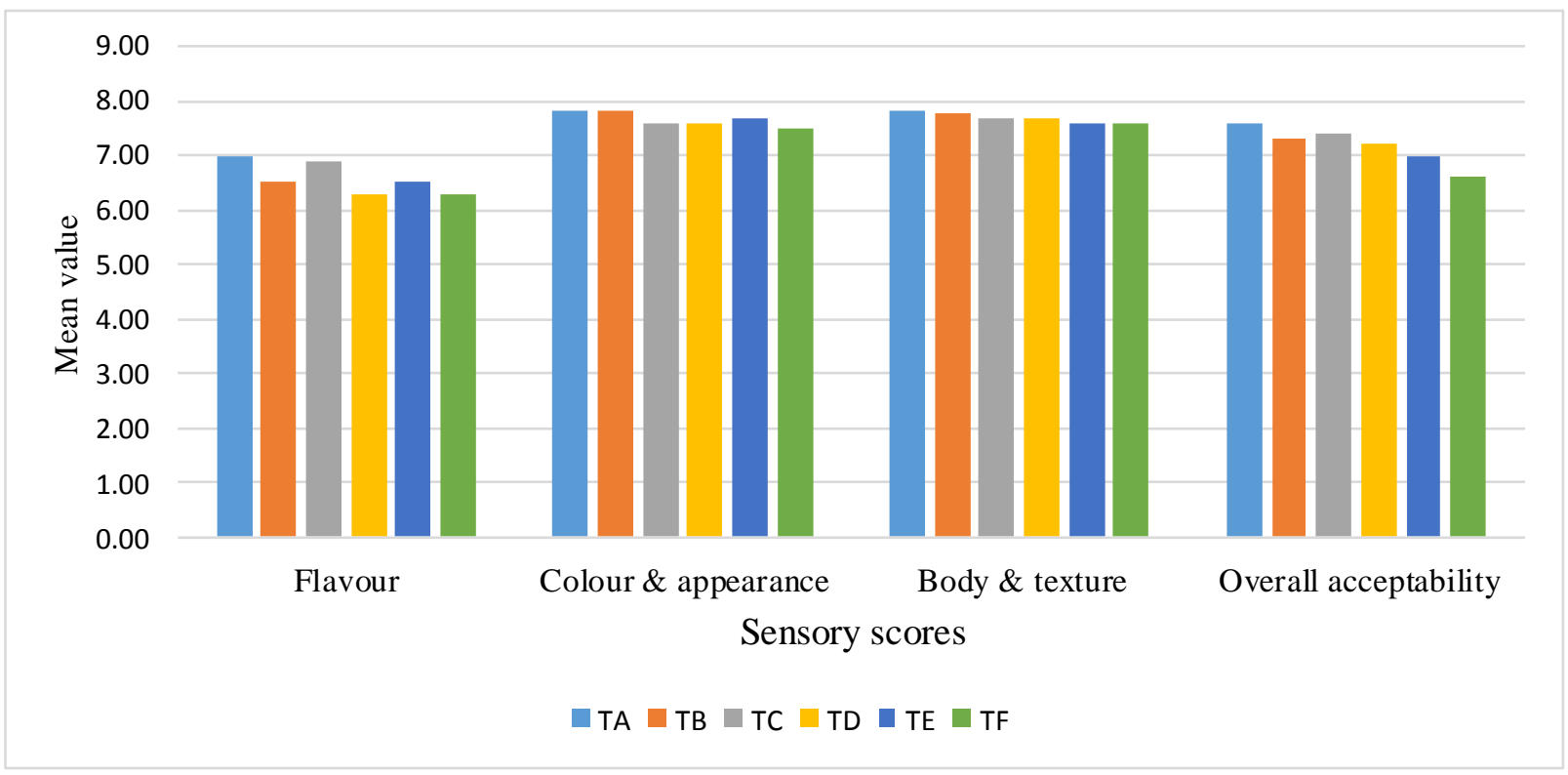


Effect of algal oil supplementation of sensory score

On the analysis for organoleptic properties, the highest Flavour score was observed by $\mathrm{T}_{\mathrm{A}}$ scoring 7.00 and 6.28 the lowest as scored by $\mathrm{T}_{\mathrm{F}}$. For Colour and appearance scores as highest as 7.80 points for both ta and $T_{B}$ while $\mathrm{T}_{\mathrm{F}}$ observed the lowest 7.50. Highest Body and texture was observed by $\mathrm{T}_{\mathrm{A}} 7.8$ and the lowest as 7.58 as scored by $\mathrm{T}_{\mathrm{F}}$. On analysis for Overall acceptability $T_{A}$ observed the highest scores 7.50 while the minimum value was scored by $T_{F}$ 6.60. On flavour it was observed that as the level of algal oil increases there is decrease in the score. On analysis for Colour and appearance it was observed that the colour and appearance decreases with the decrease in algal oil. Also for analysis for Body and texture it was observed that there is decrease in with the decrease in algal oil. Also for analysis for it was observed that there is decrease in with the decrease level of algal oil.

In the present study it was concluded that with increased level of algal oil, Flavour score decreases. This decrease can be attributed to the fact that algal oil has a fishy flavour which is not well perceived by the experts. There was no change in Colour and appearance as well as Body and texture. The overall acceptability scores decrease from 7.50 to 6.60 suggesting that the increase in algal oil contributes to the fishy flavour which decreases the score. Algal oil of sea origin is an emerging functional ingredient and is being consumed in large scale throughout the world because of the plethora of health benefits imparted by it.

\section{References}

Alessandri, G., Pagano, S., Bez, A., Benetti, A., Pozzi, S., Iannolo, G., Baronio, M.,
Invernici, G., Caruso, A. and Muneretto, C. 2004, Isolation and culture of human muscle-derived stem cells able to differentiate into myogenic and neurogenic cell lineages. Lancet. 364:1872-1883.

AOAC. 2000, The official methods of analysis of AOAC International. W. Horwitz (Ed). $17^{\text {th }}$ Edn, Washington D.C.

AOAC. 1990, 15th Official methods of Analysis. Association Official Analysis Chemists, Washington D. C. USA. 807928.

Bandyopadhyay, A. K., Ghatak, P. K. and Ray, P. R., 2016, Text Book of Analysis of milk products.

Desphande, S. S., Sathe, S. K. and Salunkhe, D. K. 1982, Functionality of Pigeon Pea Flour and Protein Concentrate. Cajan (L). Am. Chem. Sosc. Washington D. C. $1-26$.

IS: SP: 18 - Part XI. 1961, Indian Standards. Handbook of food analysis. Indian Standard Institution. Manak Bhavan. New Delhi.

IS: SP: 18 - Part XI. 1981, Indian Standards. Handbook of food analysis. Indian Standard Institution. Manak Bhavan. New Delhi.

Kulkarni, K. D., Kulkarni, D. N., Ingle and W. M., 1991, Sorghum malted \& soybean weaning food formulation: Preparation, functional properties \& nutritive value. Food Nutrition Bulletin. 13(14): 322-329.

Onwuka, G. I., 2005, Food analysis and instrumentation theory and practice. Napthali prints. Lagos.133-137.

Ranganna., 2009, Hand book of analysis and quality control for fruit and vegetable products. Tata McGraw Hill Publications. New Delhi. 


\section{How to cite this article:}

Laishram SurajSingh, Anamika Das, S.G.M Prasad, Pratishtha Srivastava, O. Chaoba Devi and John David. 2020. Effect of Incorporation of Different Levels of Algal Oil in Rice Based Ready to Eat Breakfast Cereal Mix. Int.J.Curr.Microbiol.App.Sci. 9(01): 263-268. doi: https://doi.org/10.20546/ijcmas.2020.901.030 